\title{
Terapia floral em gatos domésticos (Felis catus, Linnaeus, 1758) portadores do complexo da doença respiratória felina - estudo clínico e hematológico
}

\author{
ARAÚJO, R.F.*; RÊGO, E.W.; LIMA, E.R.; COELHO, M.C.O.C.; VASCONCELOS, K.F.; BAPTISTA, R.I.A.A.; \\ NASCIMENTO, R.C. \\ Universidade Federal Rural de Pernambuco, Departamento de Medicina Veterinária, Avenida Dom Manoel de \\ Medeiros, s/n, Dois Irmãos, CEP: 52171-039, Recife-Brasil *rfa2002@uol.com.br
}

\begin{abstract}
RESUMO: A terapia floral é considerada, atualmente, prática médica alternativa utilizada em diversas situações clínicas, constituindo possibilidade a mais de prevenção e cura de muitas doenças de natureza física e emocional. Este estudo objetivou pesquisar o efeito das essências do Sistema Brasileiro de Florais Compostos de Joel Aleixo num mesmo grupo de gatos domésticos com sinais clínicos sugestivos de Doença Respiratória Felina (DRF), tratados em diferentes momentos (M0, M1, M2, M3). Foram utilizados 20 gatos domésticos, de ambos os sexos, sem raça definida, com idade média de 5,63 $\pm 3,02$ anos criados em gatil na UFRPE. Os animais foram submetidos ao tratamento com os florais por via oral em duas etapas. Na primeira etapa com os florais Desintus Total e Helminthus Total por 14 dias, e na segunda etapa com os florais Antibius e Regius por 28 dias. Os resultados observados, quanto aos aspectos clínicos, foram redução de secreção nasal, secreção ocular e estertores pulmonares; desaparecimento de sinais clínicos como fezes alteradas, úlceras na cavidade oral, pêlos eriçados e permanência da hipertrofia dos linfonodos. Quanto aos aspectos hematológicos houve interferência nas variáveis relacionadas ao hemograma (hemoglobina, VCM, CHCM, leucócitos, linfócitos e monócitos). Conclui-se que a terapia floral mostrou-se eficaz em gatos domésticos com sinais sugestivos de DRF criados nas mesmas condições de manejo.
\end{abstract}

Palavras-chave: essências florais, complexo viral felino, gatil, análises clínicas

\begin{abstract}
Flower therapy in domestic cats (Felis catus, Linnaeus, 1758) with feline respiratory disease complex: clinical and hematological study. Flower therapy is currently considered an alternative medical practice used in several clinical situations, providing another way to prevent and cure many diseases of physical and emotional nature. This study aimed to investigate the effect of essences of the Brazilian Compound Flower System of Joel Aleixo in one same group of domestic cats showing suggestive clinical signs of Feline Respiratory Disease (FRD), treated in different moments (M0, M1, M2, M3). Twenty domestic cats, males and females, of mixed breed, with average age $5.63 \pm 3.02$, raised in the UFRPE's cattery, were used. The animals were orally treated with flower essences in two steps. Firstly with Total Desintus and Total Helminthus flower for 14 days and in the second step with Antibius and Regius for 28 days. The obtained results related to clinical aspects were a decrease in nasal and ocular discharge, and lung stertors; disappearance of clinical signal such as altered stool, ulcers in the oral cavity, bristling and hypertrophy of lymph nodes. Regarding hematological aspects, there was interference in the variables related to the blood (hemoglobin, MCV, MCHC, leucocytes, lymphocytes and monocytes). It can be concluded that flower therapy was effective in cats with signs suggestive of FRD raised under the same management conditions.
\end{abstract}

Key words: flower essences, feline viral complex, cattery, clinical analyses

\section{INTRODUÇÃO}

A doença respiratória superior é comumente descrita em felinos e rotineiramente observada na prática clínica. Trata-se de alteração provocada predominantemente por agentes infecciosos que afetam não só o trato respiratório superior, mas também os olhos e boca. O herpesvírus felino (HVF),

Recebido para publicação em 08/04/2009

Aceito para publicação em 24/08/2010

Rev. Bras. PI. Med., Botucatu, v.12, n.4, p.472-481, 2010. 
o vírus da rinotraqueíte felina, e o calicivírus felino (CVF) são os responsáveis por cerca de $90 \%$ dessas afecções. Outros patógenos envolvidos são a Bordetella bronchiseptica e a Chlamydophila felis, além de outros vírus e espécies de mycoplasmas, porém em menor proporção. Embora a vacinação contra o CVF e o HVF seja utilizada há quase 30 anos, a prevalência desses agentes na população felina não sofreu alterações (Hurley \& Sykes, 2003). O que torna a doença respiratória superior desafio na prática da medicina felina é o grande potencial de disseminação e capacidade de gerar consequências durante toda a vida do paciente. Os pacientes com afecções crônicas podem passar por crises de difícil tratamento que, por vezes, resultam na eutanásia do animal. Muitas afecções estão relacionadas à doença respiratória superior em felinos (DRSF), dentre as quais se destaca a rinosinusite, conjuntivite, ceratite, seqüestro de córnea, gengivoestomatite e os pólipos nasofaríngeos (Bannasch \& Foley, 2004).

$\mathrm{Na}$ medicina humana e na medicina veterinária, as exigências para este novo século estão pautadas na reação aos desafios e aplicação de diversas técnicas empregadas para a prevenção e a cura das doenças e, assim, melhorar a qualidade de vida do ser humano e dos animais.

Desta forma, a utilização das terapias consideradas não convencionais surge como mais um recurso nos dias de hoje, visto que os benefícios alcançados têm despertado o interesse de muitos pesquisadores.

Entre essas técnicas o emprego das essências florais, reconhecidas e aprovadas pela Organização Mundial da Saúde (OMS), segundo Naiff (2006), constitui nova abordagem na área terapêutica como valioso recurso que influi positivamente no psicoemocional do indivíduo, resgatando a saúde de forma suave e destituída de risco, possibilitando ao ser humano e aos animais adquirirem qualidade de vida.

Como os florais não podem ser analisados em laboratórios, por se tratarem de essências com energia sutil, eles necessitam ser analisados através da experimentação e observação dos efeitos (Naiff, 2006).

Considerando os benefícios relatados, a ausência de efeitos residuais e a semelhança à homeopatia, à medicina antroposófica e à medicina herbácea, a terapia floral tem despontado como coadjuvante em diversas situações clínicas, constituindo uma possibilidade a mais para a prevenção e cura de muitas doenças de natureza física e emocional (Dobbro et al., 1999).

Apesar da utilização dos florais ter iniciado na década de 30 por Bach, ratifica-se a necessidade de se pesquisar os efeitos, até então ainda não comprovados cientificamente na espécie animal, para que possa ser reconhecido como terapia única ou complementar a outros tratamentos, pois o cunho científico dado ao trabalho visa garantir a possibilidade de uma sistematização apoiada nos parâmetros vigentes.

A escolha do Sistema Brasileiro de Florais Compostos de Joel Aleixo, nesta pesquisa, deve-se à forma de preparo, com flores genuinamente brasileiras, aliada às especificidades terapêuticas. Uma das teorias acerca das propriedades terapêuticas dos florais, Naiff (2006) refere-se ao maior poder de absorção das flores de determinada terra natal (região ou nação). Apesar do Sistema Brasileiro de Florais Compostos de Joel Aleixo não possuir comprovação nos modelos adotados pela comunidade científica ocidental, obtem-se relatos de sucesso no Brasil e na Itália, onde existem trabalhos realizados por médicos da Universidade de Bolonha.

Objetiva-se, nesta pesquisa, devolver o equilíbrio e a harmonia orgânica dos animais em estudo por meio das vibrações energéticas em frequências sutis das essências do Sistema Brasileiro de Florais Compostos de Joel Aleixo, analisando os efeitos desta terapia por meio de avaliação clínica e hematológica dos animais envolvidos. Espera-se, assim com essa conduta terapêutica, obter resultados nesta patologia comum em felinos domésticos e que preocupa criadores e médicos veterinários pela sua persistência, principalmente onde há a permanência de grupos de animais no mesmo ambiente.

\section{MATERIAL E MÉTODO}

Para a realização do experimento, o projeto foi encaminhado à Comissão de Ética do DVM/UFRPE em 24/05/2007, decisão ํㅜ56/2007, processo ํㅡ 5576/ 2007, tendo parecer favorável para seu desenvolvimento.

\section{Local}

$O$ experimento foi realizado no Gatil Experimental do DMV/UFRPE, durante os meses de abril e maio de 2008. As instalações possuíam área coberta, azulejada (12 × $15 \mathrm{~m})$, com prateleiras para descanso; área de lazer ao ar livre, telada e cimentada (12 x $6 \mathrm{~m})$; área de deposição de dejetos coberta, cimentada, azulejada, telada $(3 \times 6 \mathrm{~m})$ e com saneamento; uma maternidade/berçário $(2,5 \times 1,5 \mathrm{~m})$ e dois internamentos ( $6 \times 1,5 \mathrm{~m}$ cada) os quais foram utilizados para o lote de animais escolhido para o experimento. A desinfecção do ambiente foi realizada diariamente, duas vezes ao dia, com amônia quaternária.

\section{Animais}

Foram utilizados 20 felinos domésticos oriundos do gatil, sem raça definida (SRD), com idade média $5,63 \pm 3,02$ anos, de ambos os sexos apresentando um ou mais sinais clínicos sugestivos de DRF, tais como secreção nasal, secreção ocular,

Rev. Bras. PI. Med., Botucatu, v.12, n.4, p.472-481, 2010. 
estertores pulmonares, espirros, fezes alteradas em relação à cor, odor e consistência, úlceras na cavidade oral, hipertrofia dos linfonodos, pêlos eriçados e perda de peso.

Os animais foram submetidos às mesmas condições ambientais, nutrição e cuidados veterinários baseados nas diretrizes de Raymundo (2000), sobre a utilização de animais em experimentos científicos. Todos eram everminados quatro vezes ao ano, com repetição de cada tratamento após 21 dias e recebiam vacina anti-rábica anual.

A alimentação constituiu-se de ração balanceada específica para gatos e água, ad libitum, em comedouros e bebedouros plásticos (polietileno).

Realizou-se o acompanhamento clínico, duas vezes ao dia, para observação quanto à presença de sinais clínicos. Verificou-se o peso corporal nos momentos M0 (antes do tratamento), M1 (após 14 dias de tratamento), M2 (após 28 dias de tratamento) e M3 (após 42 dias de tratamento).

O exame clínico individual foi realizado baseado nas orientações de Radostits et al. (2002) e Feitosa (2004), cujos registros foram efetuados nos momentos M0, M1, M2, e M3.

Neste experimento não foi utilizado grupo controle uma vez que se considerou o M0 (momento inicial) aquele que antecede a administração dos florais e que, portanto, serviu de parâmetro.

Os animais, ao término da pesquisa, seguiram o protocolo de doação de acordo com o projeto utilizado no gatil (após esterilização e clinicamente saudáveis).

\section{Tratamento}

Os florais foram adquiridos do Laboratório Farmacêutico Joel Aleixo, fabricados em 01/2008, lote ANTI 13.

\section{1a etapa}

Nesta fase os 20 animais receberam, diariamente, solução dos florais compostos Desintus Total e Helminthus Total na diluição de 10 gotas de cada floral para cinco mililitros de água livre de cloro (mineral), via oral, uma vez ao dia através de seringas descartáveis por 14 dias. Todos os animais também receberam água com os mesmos florais nos bebedouros simultaneamente, na proporção de 20 gotas de cada floral em água, livre de cloro (mineral) trocada duas vezes ao dia, durante 14 dias como reforço para o tratamento. O floral Desintus é composto por Bacharis trimera (Carqueja), Echinodorus grandiflorus (Chapéu-de-couro), Indigofera anil(Anis), Coleus barbatus (Boldo), Sambucus nigra (Sabugueiro), Coriandrum sativum (Coentro) e Verbascum densiflorum Bertol (Verbasco). O floral Helminthus é composto pelas flores das plantas: Ruta graviolens (Arruda), Petiveria alliacea (Guiné), Mentha piperita (Hortelã), Verbascum densiflorum
Bertol (Verbasco), Tanacetum vulgare (Catinga-damulata), Artemisia vulgaris (Artemísia) e Bidens pilosa (picão), de acordo com Aleixo (1995).

\section{2a etapa}

Após 14 dias de tratamento, os florais compostos Desintus e Helminthus foram suspensos e iniciou-se a administração dos florais compostos Antibius e Regius. Ambos foram administrados juntos na diluição de 10 gotas de cada para cinco mililitros de água mineral diariamente por via oral, uma vez ao dia durante 28 dias, e na água dos bebedouros, simultaneamente, 20 gotas de cada floral trocada duas vezes ao dia durante 28 dias, também, como reforço para o tratamento. O floral Antibius é composto pelas plantas: Pfaffia paniculata (Pfáfia), Taraxacum officinale (Dente-de-leão), Artemisia vulgaris (Artemísia), Cuphea carthagenensis (Sete-sangrias), Tropaeolum majus (Capuchinha) e própolis. O floral Regius é composto por Plantago major(Tanchagem), Tropaeolum majus (Capuchinha), Artemisia vulgaris (Artemísia), Commelina spp (Trapoeraba), Salvia officialis (Sálvia), Pfaffia paniculata (pfáfia), Rosmarinus officinalis (Alecrim), Cuphea carthagenensis (Setesangrias), Taraxacum officinale (Dente-de-leão), Sonchus oleraceus (Serralha), Echinodorus grandiflorus (chapéu de couro) e própolis (Aleixo, 1995).

\section{Exame laboratorial}

Alíquotas de sangue venoso (3-5 mL) foram coletadas de todos os animais envolvidos na pesquisa, nos momentos definidos (M0, M1, M2 e M3), por venopunção jugular com seringas descartáveis em frascos contendo solução a $10 \%$ do anticoagulante etileno diaminotetracético de sódio (EDTA) e imediatamente encaminhadas ao Laboratório de Patologia Clínica Veterinária do Hospital Veterinário/ DMV/ UFRPE.

Os hemogramas foram efetuados antes e durante os tratamentos, conforme metodologia descrita por Coles (1984). Os parâmetros de referência utilizados foram os de Ferreira Neto et al. (1978), Coles (1984), Meyer et al. (1995) e Garcia-Navarro (2005).

O hematócrito foi avaliado conforme Coles (1984), pelo micrométodo, e as determinações de hemácias, hemoglobina e contagem total de leucócitos foram obtidas por intermédio de um contador semiautomático CELM, modelo CC-530.

A contagem diferencial de leucócitos e a avaliação citomorfológica dos elementos figurados do sangue foram realizadas mediante investigação macroscópica de esfregaços corados por corante rápido panótico (NEWPROV).

\section{Análise dos resultados}

Os dados coletados através de observações dos sinais clínicos foram avaliados pela análise

Rev. Bras. PI. Med., Botucatu, v.12, n.4, p.472-481, 2010. 
descritiva dos percentuais. A análise estatística dos dados quantitativos obtidos para variável peso e para as variáveis relacionadas com o hemograma realizouse através da análise de variância, considerando como fonte de variação os momentos (M0, M1, M2 e M3) com intervalo de 14 dias, e a comparação entre as médias das variáveis estudadas, calculada através do Teste de Tukey ao nível de $5 \%$ de probabilidade (Reis, 2003).

\section{RESULTADO E DISCUSSÃO}

Conforme o protocolo estabelecido para a administração dos florais brasileiros, iniciou-se o tratamento administrando-se os florais Compostos Desintus Total e Helminthus. O floral Helminthus foi utilizado para eliminar os endoparasitos que debilitam o indivíduo. O floral Desintus auxiliou na desintoxicação alimentar, por drogas, quimioterapia e radioterapia e finalizou a limpeza do organismo.

No momento seguinte deu-se continuidade ao tratamento utilizando-se florais específicos baseados na avaliação dos sinais clínicos. Para a DRF foram escolhidos os florais Antibius e Regius. $O$ Antibius teve ação de recompor o organismo das adversidades externas que atingem o indivíduo. Atuou como antibiótico. O Regius teve ação de despertar a capacidade de reconstruir, auxiliou na regeneração a partir de aminoácidos que reestruturaram os tecidos.

\section{Peso corporal dos animais}

Verificou-se discreta perda de peso no M2 (após 28 dias de administração dos florais) mantendose este peso no M3 (Tabela1). A perda de peso observada não teve relação com a alimentação, uma vez que a ração foi mantida a mesma antes e durante o experimento. Por outro lado o estresse, confinamento e manipulação dos animais podem ter influenciado este resultado. Entretanto o baixo valor do coeficiente de variação para peso $(18,96 \%)$ reflete a estabilidade real desta variável (Tabela 1). Possivelmente a perda de peso mostrou-se benéfica para o tratamento indicando a limpeza do organismo. Este fato sustenta o pensamento que norteia a terapia com florais brasileiros, justificado pela ação dos florais compostos utilizados no M1 (14 dias de tratamento) e que foram responsáveis pela desintoxicação orgânica.

O fato da perda de peso ocorrer após o término do período de desintoxicação, pode sugerir que a dosagem não foi suficiente para fazer efeito durante os 14 dias iniciais. Mesmo assim, percebese que iniciado o tratamento específico com os florais Antibius e Regius, o peso foi mantido, o que foi importante para o momento seguinte.

\section{Sinais Clínicos}

A secreção nasal (Figura 1) estava presente antes da administração dos florais (M0) em 35\% (07)
TABELA 1. Valores médios do peso corpóreo de gatos submetidos à terapia floral no gatil do DMV/UFRPE, em diferentes momentos (M0;M1;M2 e M3).

\begin{tabular}{ccc}
\hline Momentos & Média $(\mathbf{K g})$ & ${ }^{*} \mathrm{EC}(\mathbf{x = 0 , 0 5 \% )}$ \\
\hline 0 & 3,80 & $\mathrm{a}$ \\
1 & 3,80 & $\mathrm{a}$ \\
2 & 3,70 & $\mathrm{a}$ \\
3 & 3,70 & $\mathrm{a}$ \\
\hline${ }^{* *} \mathrm{CV}(\%)$ & $(-)$ & 18,962 \\
\hline
\end{tabular}

*EC- Estatística Comparativa onde letras iguais indicam que não houve diferença estatística entre as médias quando utilizado o teste de Tuckey

dos animais e no $\mathrm{M} 1$ ocorreu queda de $30 \%$, vindo a desaparecer no M2, retornando a aparecer no M3 em $10 \%$ (02) dos animais. Notou-se, portanto, que a atuação do floral não foi suficiente na manutenção desta condição e, provavelmente o retorno deste sinal somou-se a possível queda de imunidade provocada pelo estresse na manipulação dos animais que poderiam estar na condição de portadores assintomáticos. Mesmo assim, este dado sugere que apesar da administração dos florais não ser suficiente para o completo desaparecimento deste sinal clínico, ao final do tratamento ocorreu redução de $25 \%$ (05) em relação ao número inicial de animais com este achado clínico. A secreção nasal é sinal clínico primário, mas não obrigatório no complexo da DRF, uma vez que a condição do animal portador pode torná-lo aparentemente assintomático (Jones et al., 2000; Spinosa et al., 2002).

A secreção ocular estava presente em $70 \%$ (14) dos animais. Ao serem submetidos ao tratamento, houve queda de $25 \%$ (05) no M1 e $65 \%$ (13) no M2, porém observou-se que houve retorno de $50 \%$ (10) desses sinais no $\mathrm{M} 3$ em relação ao M0. A dosagem utilizada pode não ter sido suficiente para a restauração do equilíbrio orgânico. Entretanto, comparando-se ao número de animais com este sinal clínico inicialmente $(70 \% / 14)$, observou-se que ocorreu redução de 20\% (04) (Figura 1). Desta forma, o resultado apresentado sugere que os florais podem ter contribuído para a redução. A descarga ocular é um sinal subsequente (Knowles \& Gaskell, 1991) e a forma aguda podem estar caracterizadas por ocorrência súbita (Ettinger \& Feldman, 1995), acredita-se que este tenha sido mais um fator desencadeador do retorno dos sintomas, uma vez que $50 \%$ (10) é taxa considerada alta, não justificando as circunstâncias anteriores.

Os espirros foram observados em $5 \%(01)$ dos animais antes do tratamento com os florais (M0). No M1 e no M2 ocorreu o desaparecimento dos mesmos indicando o possível efeito dos florais, entretanto no M3 eles reapareceram e numa

Rev. Bras. PI. Med., Botucatu, v.12, n.4, p.472-481, 2010. 


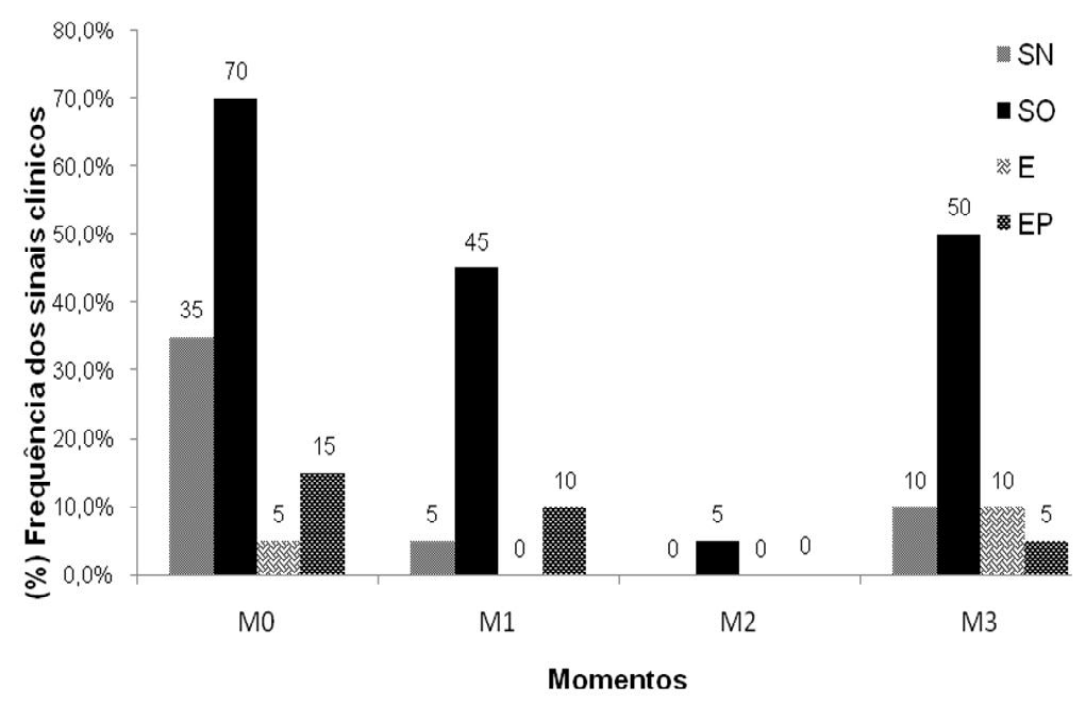

FIGURA 1. Frequência dos sinais clínicos: secreção nasal (SN), secreção ocular (SO) espirros (E), estertores pulmonares (EP) e hipertrofia dos linfonodos (Linf) em gatos domésticos (Felis catus), submetidos a tratamento com os florais de Joel Aleixo no M0, M1, M2 e M3, no gatil do DMV/UFRPE, abril e maio/2008.

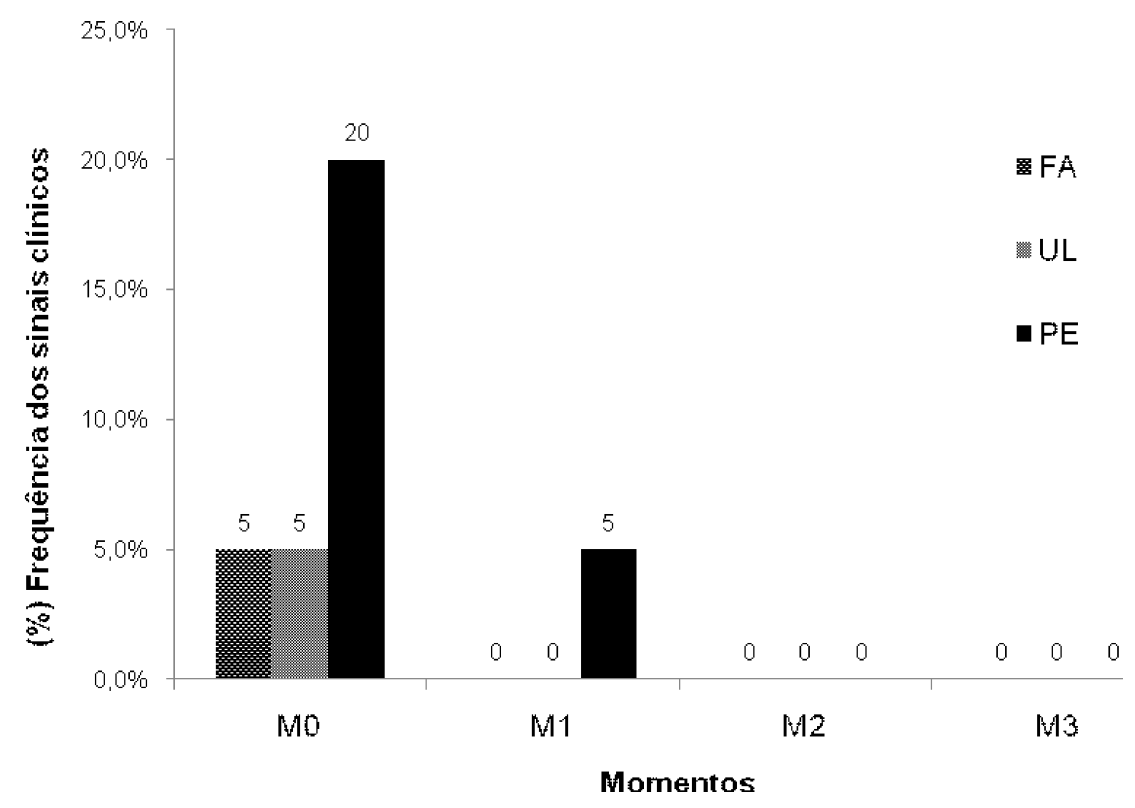

FIGURA 2. Frequência dos sinais clínicos: fezes alteradas (FA), úlceras orais (UL) e pêlos eriçados (PE) em gatos domésticos (Felis catus), submetidos a tratamento com os florais de Joel Aleixo no M0, M1, M2 e M3, no gatil do DMV/UFRPE, abril e maio/2008.

incidência maior, 10\% (02) dos animais (5\% a mais) (Figura 1). Talvez este fato seja explicado pela DRF apresentar períodos de latência (situação de portadores assintomáticos) conforme relatam Jones et al. (2000) e Spinosa et al. (2002) ou ainda por agudização do quadro clínico, segundo Ettinger \& Feldman (1995). Outra hipótese a ser considerada é a dosagem dos florais Antibius e Regius que pode não ter sido suficiente para eliminar este sinal.
Portanto, supõe-se que muitos animais estando na fase crônica necessitariam de administração mais prolongada dos florais.

Os estertores pulmonares estavam presentes em $15 \%$ (03) dos animais no momento inicial (M0) e no M1 ocorreu uma queda de $5 \%$ (01), desaparecendo no M2 e no M3 5\% (01) voltaram a apresentar este sinal (Figura 1); consequentemente, pode estar associado aos casos onde o animal 
apresenta pneumonia atribuída à infecção secundária ou por cepa mais virulenta de calicivírus, o que poderia causar maior resistência orgânica, isto vem corroborar com os resultados de Gaskell et al. (2006). Mesmo assim percebeu-se que os florais conseguiram reduzir estes achados em 10\%. Entretanto constatou-se que para este sinal a dosagem dos florais de desintoxicação e os 14 dias de tratamento específico não foram suficientes para o desaparecimento.

Fezes alteradas em relação à consistência, odor e coloração (Figura 2) foram observadas em 5\% (01) dos animais que apresentavam tenesmo e diarréia antes do tratamento e no M1 esta alteração desapareceu, sugerindo que os florais compostos têm a finalidade de atuar auxiliando na eliminação de toxinas e redução de sintomas conforme cita Aleixo (1995), por consequência, o desaparecimento deste sinal clínico. Sabe-se que doenças de outros sistemas orgânicos podem apresentar consequências sobre o sistema respiratório e devem ser considerados (Ettinger \& Feldman, 1995). Portanto, embora este não seja sinal específico da DRF é um fator desencadeante, uma vez que esta alteração debilita o animal diminuindo a resistência e ainda compromete a resposta imunológica dos portadores assintomáticos.

Úlcera na cavidade oral (língua) foi observada inicialmente em 5\% dos animais, no M1 desapareceram (Figura 2). As lesões orais, conforme relatam Hurley \& Sykes (2003) são muito comuns na infecção pelo CVF em gatos com doença oral crônica. Entretanto, mesmo com a cronicidade pode ser percebido que os florais de desintoxicação agiram de forma rápida e benéfica. O floral Regius com efeito cicatrizante e responsável pela regeneração e reparação de tecidos foi fundamental no desaparecimento deste sinal clínico.

Pêlos eriçados foram observados em $20 \%$ dos animais antes do tratamento com os florais no M0. No M1 reduziu para $5 \%(01)$, vindo a desaparecer no M2 (Figura 2). Mesmo que este sinal, não seja indicativo da DRF, é considerado alteração encontrada em muitas doenças debilitantes (Radostits et al., 2002). Quando associado à gengivoestomatite ocorre diminuição dos hábitos de limpeza, resultando em pelagem oleosa e descuidada (Foley, 2006). Foi percebido que os florais contribuíram com a redução deste sinal clínico e os animais que apresentaram úlceras, inicialmente, retornaram aos hábitos de limpeza melhorando a condição dos pêlos. Os animais que apresentaram debilidade recuperaram o estado geral.

Redução de atividade foi observada no M1, durante os 14 dias de desintoxicação e desapareceu no M2 (Figura 3), o que sugere a influência dos florais no processo de limpeza orgânica, uma vez que os florais compostos atuam diretamente como coadjuvantes na eliminação de toxinas (Aleixo, 2007).
Como pode ser observado, apesar de nenhum animal apresentar inicialmente este sinal clínico, foi utilizado como parâmetro por ser evidenciado durante as observações realizadas no experimento, e que coincide com a administração dos florais de desintoxicação. Este fato sugere que o processo de limpeza causa desconforto e debilita o animal por atuar na eliminação dos expurgos pelos emunctórios naturais através das secreções, fezes, urina, suor, saliva e gânglios linfáticos.

Hipertrofia de linfonodos foi evidenciada ao início do tratamento com os florais em 55\% (11) dos gatos, e a partir dos 14 dias de administração dos florais de desintoxicação (M1) ocorreu maior incidência desta alteração chegando a acometer $80 \%$ dos animais do grupo (Figura 3), o que pode sugerir intensa atividade fagocítica executada por macrófagos e pela intensa atividade dos linfócitos para estimular a resposta imune (Tizard, 1998). No M2 ocorreu o desaparecimento desta alteração que coincide com o início da administração dos florais de tratamento, entretanto, reaparece no M3 (aos 42 dias de tratamento) em $70 \%$ dos gatos. Este fato sugere a persistência da atividade fagocítica dos macrófagos como componentes fundamentais do sistema imune (Ettinger \& Feldman, 1995); nas condições inflamatórias em que são frequentemente associadas com a estimulação antigênica e no combate à possível infecção acometida nestes animais ou outra infecção, haja vista a imunodepressão provocada que estimularia a linfocitose (Rebar et al., 2003).

$\mathrm{Na}$ avaliação clínica dos animais levou-se em conta a hipertrofia de um ou mais linfonodos independente da localização, apesar dos gatos acometidos pela B.bronchiseptica apresentarem linfoadenomegalia submandibular (Gaskell et al., 2006). Porém, como a incidência da DRF persistia naquela população por longo período, provavelmente tornou-se crônica na maioria dos animais, justificando assim o retorno da atividade linfocítica para estimular a resposta imune. Por ter retornado após os 14 dias de desintoxicação e 14 dias de tratamento específico, deduz-se que o tempo de administração e/ou a dosagem dos florais Desintus e Helminthus não foram suficientes para eliminar este sinal clínico.

A administração dos florais inicia-se com a tomada desses florais por pelo menos uma semana de desintoxicação e em seguida dá-se início concomitantemente com o tratamento específico. No caso desta pesquisa estabeleceu-se a administração em momentos diferentes com o objetivo de se avaliar a ação dos florais em cada fase.

\section{Avaliação das variáveis do hemograma}

Os resultados obtidos no hemograma (Tabela 2), de acordo com os momentos (M0, M1, M2 e M3), evidenciam diferenças estatisticamente significativas 


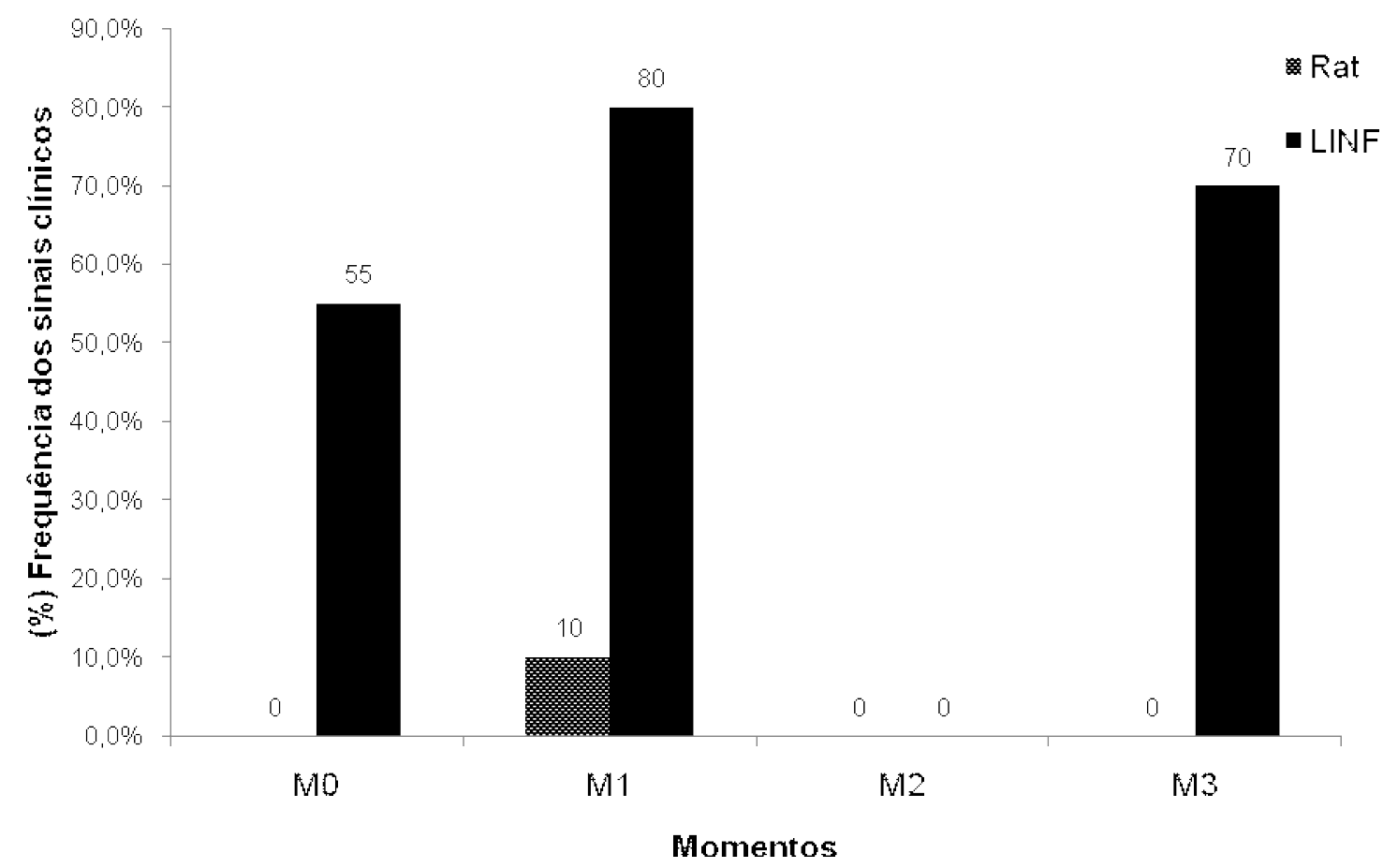

FIGURA 3. Frequência dos sinais clínicos: redução de atividade (Rat) e hipertrofia dos linfonodos (Linf) em gatos domésticos (Felis catus), submetidos a tratamento com os florais de Joel Aleixo no M0, M1, M2 e M3, no gatil do DMV/UFRPE, abril e maio/2008.

TABELA2. Valores médios e coeficientes de variação das variáveis quantitativas relacionadas com o hemograma de gatos com Doença Respiratória Felina, submetidos à terapia floral de acordo com os momentos: M0; M1; M2 e M3.

\begin{tabular}{l|cccc|c}
\hline \multirow{2}{*}{ Variável } & \multicolumn{4}{|c|}{ Momentos } & CV \\
\cline { 2 - 5 } & $\mathbf{0}$ & $\mathbf{1}$ & $\mathbf{2}$ & $\mathbf{3}$ & (\%) \\
\hline Hemácias $\left(\times 10^{6} \mu \mathrm{L}^{-1}\right)$ & $7,66 \mathrm{a}$ & $8,37 \mathrm{a}$ & $7,93 \mathrm{a}$ & $6,99 \mathrm{a}$ & 22,09 \\
Hemoglobina $\left(\mathrm{gdL}^{-1}\right)$ & $11,54 \mathrm{ab}$ & $12,22 \mathrm{~b}$ & $11,27 \mathrm{ab}$ & $10,52 \mathrm{a}$ & 15,62 \\
Hematócrito $(\%)$ & $34,70 \mathrm{a}$ & $32,40 \mathrm{a}$ & $33,90 \mathrm{a}$ & $31,60 \mathrm{a}$ & 13,3 \\
VCM $(\mathrm{fl})$ & $45,27 \mathrm{ab}$ & $40,30 \mathrm{a}$ & $48,19 \mathrm{ab}$ & $45,30 \mathrm{~b}$ & 15,94 \\
CHCM $(\%)$ & $33,18 \mathrm{a}$ & $37,73 \mathrm{~b}$ & $33,31 \mathrm{ab}$ & $33,28 \mathrm{a}$ & 6,5 \\
Leucócitos $\left(\mu \mathrm{L}^{-1}\right)$ & $17575 \mathrm{ab}$ & $20605 \mathrm{~b}$ & $17225 \mathrm{ab}$ & $12060 \mathrm{a}$ & 46,72 \\
Bastonetes $\left(\mu \mathrm{L}^{-1}\right)$ & $447,40 \mathrm{a}$ & $481,17 \mathrm{a}$ & $344,63 \mathrm{a}$ & $282,25 \mathrm{a}$ & 74,46 \\
Segmentados $\left(\mu \mathrm{L}^{-1}\right)$ & $10885,85 \mathrm{a}$ & $13727,45 \mathrm{a}$ & $10752,65 \mathrm{a}$ & $9084,37 \mathrm{a}$ & 58,04 \\
Eosinófilos $\left(\mu \mathrm{L}^{-1}\right)$ & $1116,05 \mathrm{a}$ & $884,65 \mathrm{a}$ & $977,50 \mathrm{a}$ & $1184,30 \mathrm{a}$ & 70,13 \\
Linfócitos $\left(\mu \mathrm{L}^{-1}\right)$ & $4945,85 \mathrm{ab}$ & $5567,55 \mathrm{~b}$ & $4772,40 \mathrm{ab}$ & $2820,35 \mathrm{a}$ & 65,61 \\
Monócitos $\left(\mu \mathrm{L}^{-1}\right)$ & $420,47 \mathrm{ab}$ & $626,00 \mathrm{~b}$ & $350,29 \mathrm{ab}$ & $201,60 \mathrm{a}$ & 72,77 \\
\hline
\end{tabular}

Para uma mesma variável, médias seguidas de letras iguais na mesma linha, não deferem estatisticamente ao nível de 0,05 pelo Teste de Tuckey

( $p>0,05)$ quando comparadas a hemoglobina, volume corpuscular médio (VCM), concentração de hemoglobina corpuscular média (CHCM), leucócitos, linfócitos e monócitos. As demais variáveis não apresentaram diferenças estatísticas entre os momentos estudados nos animais com DRF. Os altos valores do coeficiente de variação em todas as variáveis da série branca refletem a instabilidade real das mesmas.

O hemograma pode não apresentar alterações nos casos de doenças em estágios avançados e crônicas, conforme Coles (1984) e Meyer et al. (1995). 
Apesar da variação nos resultados obtidos, os valores médios gerais para o hemograma apresentaram valores dentro dos parâmetros considerados normais para gatos (Ferreira Neto et al., 1978; Coles, 1984; Meyer et al., 1995; Garcia-Navarro, 2005), exceto o número de leucócitos, que no M1 ultrapassou o limite da normalidade. $O$ estudo da disposição leucocitária reflete a reação do organismo animal frente aos agentes tóxicos e infecciosos (Rebar et al., 2003).

$\mathrm{Na}$ análise dos resultados obtidos para o hemograma na comparação dos valores médios das variáveis entre os momentos (Tabela 3), verificou-se que entre $\mathrm{M} 1-\mathrm{M} 0$ apenas os valores do VCM e CHCM foram estatisticamente significativos $(p>0,05)$. Entre M3-M0 houve diferença estatística $(p>0,05)$ para hemácias, hemoglobina, hematócrito, leucócitos, linfócitos e monócitos, com visível melhora clínica, sugerindo haver influência da terapia nos animais com DRF, possivelmente através da melhoria da oxigenação do sangue e aumento das defesas orgânicas contra os agentes infecciosos durante o período de desintoxicação e tratamento.

A análise dos resultados entre os momentos demonstraram que houve diferença significativa $(p>0,05)$ entre M2-M1 para CHCM; entre M3-M1 houve diferença significativa $(p<0,05)$ para hemácias, hemoglobina, VCM, CHCM, leucócitos, segmentados, linfócitos e monócitos e entre M3-M2 houve diferença significativa $(p>0,05)$ para hemoglobina, leucócitos, linfócitos. As variáveis bastonetes e eosinófilos não apresentaram diferenças estatisticamente significativas na comparação dos valores médios entre os diferentes momentos apesar dos bastonetes estarem relacionados com os processos infecciosos e inflamatórios.

TABELA 3. Comparação dos valores médios e coeficientes de variação das variáveis quantitativas relacionadas com o hemograma de gatos com Doença Respiratória, submetidos à terapia floral de acordo com os momentos: M0; M1; M2 e M3.

\begin{tabular}{lrrrrrr}
\hline \multirow{2}{*}{ Variáveis } & \multicolumn{6}{c}{ T Calculado } \\
\cline { 2 - 7 } & \multicolumn{7}{c}{ Momentos } \\
\cline { 2 - 7 } & (M1-M0) & (M2-M0) & (M3-M0) & (M2-M1) & (M3-M1) & (M3-M2) \\
\hline Hemácias (He) & $1,63 \mathrm{~ns}$ & $0,39 \mathrm{~ns}$ & $2,53^{*}$ & $0,52 \mathrm{~ns}$ & $3,16^{*}$ & $1,43 \mathrm{~ns}$ \\
Hemoglobina (Hb) & $1,28 \mathrm{~ns}$ & $0,72 \mathrm{~ns}$ & $2,51^{*}$ & $1,53 \mathrm{~ns}$ & $3,02^{*}$ & $1,82^{*}$ \\
Hematócrito (Ht) & $1,91 \mathrm{~ns}$ & $0,72 \mathrm{~ns}$ & $2,55^{*}$ & $1,14 \mathrm{~ns}$ & $0,66 \mathrm{~ns}$ & $1,85 \mathrm{~ns}$ \\
VCM & $2,94^{*}$ & $0,64 \mathrm{~ns}$ & $0,55 \mathrm{~ns}$ & $1,52 \mathrm{~ns}$ & $2,91^{*}$ & $0,63 \mathrm{~ns}$ \\
CHCM & $3,13^{*}$ & $0,59 \mathrm{~ns}$ & $0,54 \mathrm{~ns}$ & $3,27^{*}$ & $3,28^{*}$ & $1,14 \mathrm{~ns}$ \\
Leucócitos (Leuc) & $1,40 \mathrm{~ns}$ & $0,17 \mathrm{~ns}$ & $3,36^{*}$ & $1,20 \mathrm{~ns}$ & $3,56^{*}$ & $3,39^{*}$ \\
Bastonetes (Bt) & $0,31 \mathrm{~ns}$ & $0,90 \mathrm{~ns}$ & $0,71 \mathrm{~ns}$ & $0,74 \mathrm{~ns}$ & $0,59 \mathrm{~ns}$ & $0,45 \mathrm{~ns}$ \\
Segmentados Seg) & $1,56 \mathrm{~ns}$ & $0,07 \mathrm{~ns}$ & $1,61 \mathrm{~ns}$ & $1,30 \mathrm{~ns}$ & $2,77^{*}$ & $1,32 \mathrm{~ns}$ \\
Eosinófilos (Eos) & $0,99 \mathrm{~ns}$ & $0,67 \mathrm{~ns}$ & $0,12 \mathrm{~ns}$ & $0,50 \mathrm{~ns}$ & $0,54 \mathrm{~ns}$ & $0,39 \mathrm{~ns}$ \\
Linfócitos (Lin) & $0,76 \mathrm{~ns}$ & $0,18 \mathrm{~ns}$ & $3,18^{*}$ & $0,63 \mathrm{~ns}$ & $3,03^{*}$ & $2,62^{*}$ \\
Monócitos (Mon) & $0,91 \mathrm{~ns}$ & $1,24 \mathrm{~ns}$ & $2,89^{*}$ & $1,82 \mathrm{~ns}$ & $2,71^{*}$ & $1,59 \mathrm{~ns}$ \\
\hline
\end{tabular}

O teor de hemoglobina no M1 (Figura 4) apresentou o maior valor que é justificado pelo importante papel da hemoglobina como componente principal das hemácias e responsável no transporte do oxigênio para os tecidos (Garcia Navarro, 2005). Este fato vem corroborar com o efeito da desintoxicação orgânica realizada pelos florais Desintus e Helminthus neste momento.

Ocorreram oscilações do VCM e CHCM (Figura 5). O VCM apesar de ter diminuido no M1 manteve-se nos níveis de normalidade conforme os parâmetros dos pesquisadores Ferreira Neto et al. (1978); Coles (1984); Meyer et al. (1995) e GarciaNavarro (2005). O mesmo não aconteceu para a variável $\mathrm{CHCM}$ que apresentou aumento nos níveis acima da normalidade coincidindo com o aumento

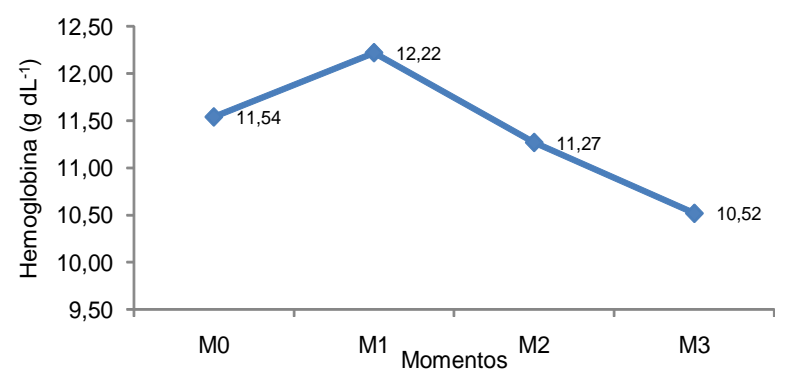

FIGURA 4. Valores médios de hemoglobina $\left(\mathrm{g} \mathrm{dL}^{-1}\right)$ de sangue em gatos domésticos (Felis catus) submetidos a tratamento com os florais de Joel Aleixo no M0, M1, M2 e M3, no gatil do DMV/UFRPE, abril e maio/2008. 


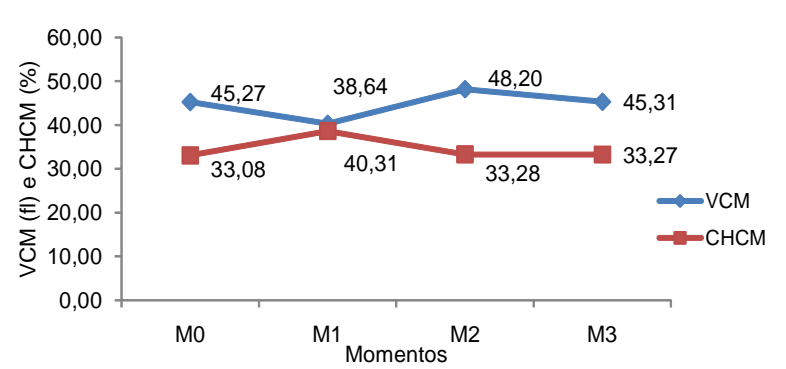

FIGURA 5. Valores médios do volume corpuscular médio (fl) e da concentração de hemoglobina corpuscular média (\%) de sangue em gatos domésticos (Felis catus) submetidos a tratamento com os florais de Joel Aleixo no M0, M1, M2 e M3, no gatil do DMV/UFRPE, abril e maio/2008.

do teor hemoglobina na fase de desintoxicação. As variações ocorridas no VCM e CHCM estão na dependência do hematócrito, hemoglobina e hemácias.

Para a média total de leucócitos circulantes observou-se aumento no M1 seguida de redução nos M2 e M3 (Figura 6). Este aumento pode estar associado ao estresse emocional, que causa a migração de neutrófilos do sangue marginal para o sangue circulante, conforme cita Meyer et al. (1995). No M2 e M3 os resultados encontrados mesmo estando nos níveis de normalidade para a espécie (Ferreira Neto et al., 1978; Coles, 1984; Meyer et al., 1995; Garcia-Navarro, 2005) mostram-se em declínio. Considerando que a função dos leucócitos nos processos inflamatórios e imunológicos é o de combater agentes (Rebar et al., 2003) e os florais Desintus e Helminthus são responsáveis pela eliminação de toxinas do organismo, sugere-se que estes florais possam ter contribuído para o redução da infecção.

$\mathrm{O}$ número de linfócitos aumentou no $\mathrm{M} 1$ (Figura 7) e observou-se queda a partir do M2. O estresse pode elevar o número de linfócitos,

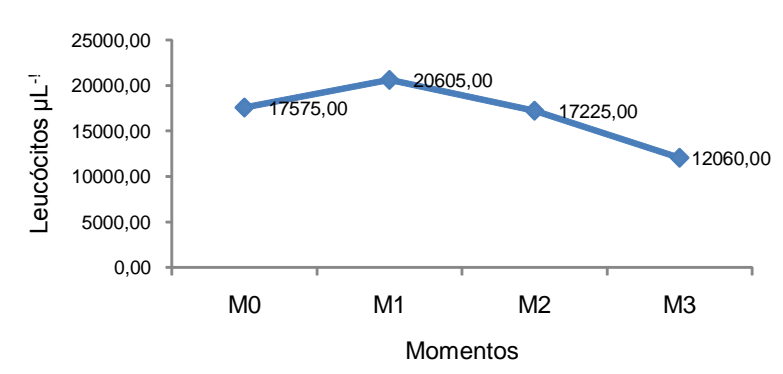

FIGURA 6. Valores médios de leucócitos $\mu \mathrm{L}^{-1}$ de sangue em gatos domésticos (Felis catus), submetidos a tratamento com os florais de Joel Aleixo no M0, M1, M2 e M3, no gatil do DMV/UFRPE, abril e maio/2008. especialmente no gato. Este aumento inicial também é sugestivo da estimulação antigênica citada por Rebar et al. (2003), que coincide com intensa atividade dos linfonodos visualizada na Figura 3, justificando a hipertrofia destas glândulas (fagocitose executada por macrófagos) para combater as substâncias tóxicas do organismo, a partir dos 14 dias de desintoxicação. Sugere-se que os florais possam ter contribuído na recuperação e imunidade dos animais. Os níveis desta variável mantiveram-se dentro da normalidade.

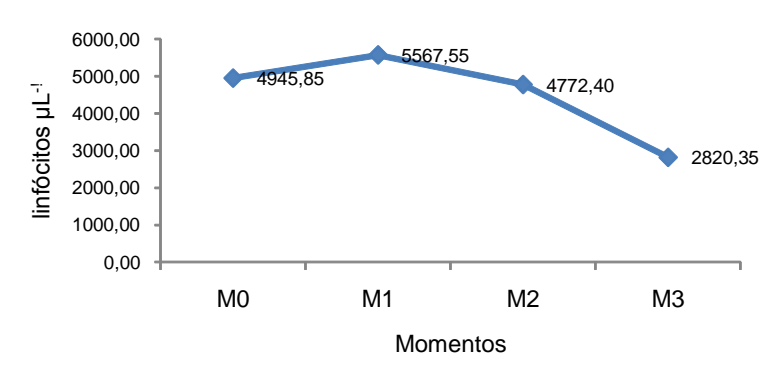

FIGURA 7. Valores médios de linfócitos $\mu \mathrm{L}^{-1}$ de sangue em gatos domésticos (Felis catus), submetidos a tratamento com os florais de Joel Aleixo no M0, M1, M2 e M3, no gatil do DMV/UFRPE, abril e maio/2008.

O número dos monócitos (Figura 8) aumentou no M1e no M3 ocorreu o menor valor. O alto valor do coeficiente de variação revela a instabilidade dessa variável. O resultado sugere que os florais estimularam as defesas do organismo conforme a função dos monócitos (Ettinger \& Feldman, 1995). Provavelmente este fato provocou aumento da produção de monócitos na medula óssea que resultou, como consequência, o aumento no sangue circulante. Também de acordo com Tizard (1998), os neutrófilos após atacarem o primeiro material estranho e morrerem atraem os macrófagos para o local da invasão, justificando da mesma forma este aumento no M1.

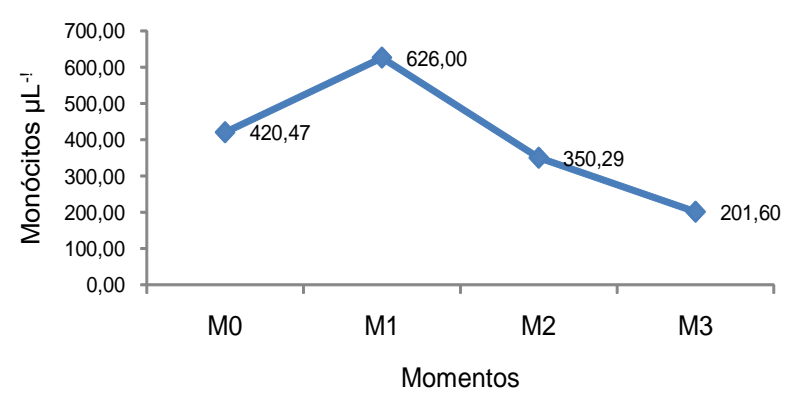

FIGURA 8. Valores médios de monócitos $\mu \mathrm{L}^{-1}$ de sangue em gatos domésticos (Felis catus), submetidos a tratamento com os florais de Joel Aleixo no M0, M1, M2 e M3, no gatil do DMV/UFRPE, abril e maio/2008. 


\section{CONCLUSÃO}

Com base nos resultados obtidos e nas condições em que o experimento foi realizado, podese concluir que:

- A terapia floral é eficaz para o desaparecimento dos sinais clínicos: fezes alteradas, úlceras na cavidade oral e pêlos eriçados, em gatos domésticos com sinais sugestivos de DRF.

- Por ser isenta de efeitos colaterais, não oferecendo risco à saúde animal, a terapia floral mostrase viável como terapia coadjuvante no tratamento da DRF, visto que minimizou os sinais clínicos secreção nasal, secreção ocular e estertores pulmonares.

- A diminuição progressiva dos valores das hemácias e da hemoglobina, sem alteração dos índices eritrocitários, ainda precisa ser avaliada na terapia floral, a fim de elucidar a verdadeira causa.

- A terapia floral apresenta modificações nas variáveis do hemograma (leucócitos, linfócitos e monócitos), influenciadas, provavelmente, pelo bem estar físico apresentado pelos gatos domésticos com sinais sugestivos de DRF.

\section{REFERÊNCIA}

ALEIXO, J. Essências florais brasileiras. São Paulo: Ground, 1995. 185p.

ALEIXO, J. Oitavo passo. São Paulo: Do Autor, 2007. 254p. BANNASCH, M.J.; FOLEY, J.E. Epidemiologic evaluation of multiple respiratory pathogens in cats in animal shelters. Journal of Feline Medicine and Surgery, v.7, p.109-19, 2004.

COLES, E.H. Patologia clínica veterinária. 3.ed. São Paulo: Manole, 1984. 566p.

DOBBRO, E.R.L. et al. Ansiedade do adolescente vítima de queimadura e o uso das essências florais. In: GIMENES, O.M.P.V.; SILVA, M.J.P. (Eds.). Florais: alternativa saudável: pesquisas revelam tratamentos e resultados dessa terapia. São Paulo: Gente, 1999. cap. 4, p.113-45.

ETTINGER, S.J.; FELDMAN E.C. Textbook of veterinary internal medicine. 4.ed. Philadelphia: W. B. Saunders, 1995. v.1, p.425-33.
FEITOSA, F.L.F. Semiologia veterinária: a arte do diagnóstico. São Paulo: Roca, 2004. 807p.

FERREIRA NETO, J.M.; VIANA, E.S.; MAGALHÃES, L.M. Patologia clínica veterinária. Belo Horizonte: Rabelo e Brasil, 1978. 932p.

FOLEY, J.E. Calicivirus: spectrum of disease. In: AUGUST, J.R. Consultations in feline internal medicine. 5.ed. $\mathrm{s} / \mathrm{l}$.: Elsevier Inc, 2006. p.3-9.

GARCIA-NAVARRO, C.E.K. Manual de hematologia veterinária. São Paulo: Varela, 2005. 206p.

GASKELL, R.M.; RADFORD, A.D.; DAWSON, S.D. Doença respiratória infecciosa felina. In: CHANDLER, E.A.; GASKELL, C.J.; GASKELL, R.M. (Eds.). Clínica e terapêutica em felinos. 3.ed. São Paulo: Roca, 2006. p.472-84.

HURLEY, K.F.; SYKES, J.E. Update on feline calicivirus: new trends. The Veterinary Clinics of North America: Small Animal Practice, v.33, p.759-72, 2003.

JONES, T.C. et al. Patologia veterinária. 6.ed. São Paulo: Manole, 2000. p.185-7.

KNOWLES, J.O.; GASKELL, R.M. Control of upper respiratory diseases in multiple cat households and catteries. In:AUGUST, J.R. (Ed.) Feline internal medicine. 9.ed. Philadelphia: W. B. Saunders, 1991. p.563-9.

MEYER, D.J.; COLES, E.H.; RICH, L.J. Medicina de laboratório veterinário: interpretação e diagnóstico. São Paulo: Roca, 1995. 308p.

NAIFF, N. Florais do mundo. Rio de Janeiro: Nova Era, 2006. 279p.

RADOSTITS, O.M.; MAYHEW, I.G; HOUSTON, D.M. Exame clínico e diagnóstico em veterinária. Rio de Janeiro: Guanabara Koogan, 2002. 591p.

RAYMUNDO, M.M. Os deveres dos pesquisadores para com os animais de experimentação: uma proposta de auto-regulamentação. 2000. 103p. Dissertação (Mestrado em Ciências Biológicas-Fisiologia) Universidade Federal do Rio Grande do Sul, Porto Alegre. REBAR, A.H. et al. Guia de hematologia para cães e gatos. São Paulo: Rocca, 2003. 291p.

REIS, J.C. Estatística aplicada à pesquisa em ciência veterinária. Olinda: JCR, 2003. 651p.

SPINOSA, H.S. et al. Farmacologia aplicada a medicina veterinária. 3.ed. Rio de Janeiro: Guanabara Koogan, 2002. p.441-604.

TIZARD, I.R. Imunologia veterinária: uma introdução. 5.ed. São Paulo: Roca, 1998. 545p. 